\title{
Lexis
}

Journal in English Lexicology

$18 \mid 2021$

Lexical learning and teaching

\section{Understanding the distributed practice effect and its relevance for the teaching and learning of L2 vocabulary}

Amanda Edmonds, Emilie Gerbier, Katerina Palasis and Shona Whyte

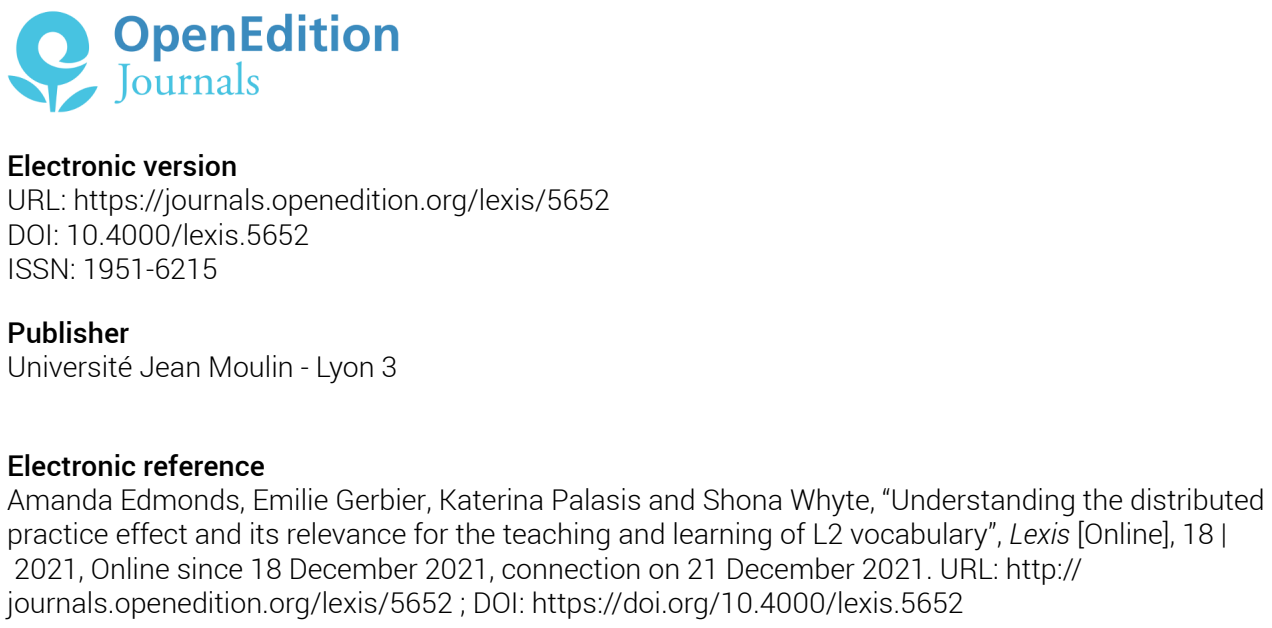

This text was automatically generated on 21 December 2021.

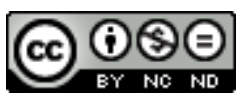

Lexis is licensed under a Creative Commons Attribution-NonCommercial-NoDerivatives 4.0 International License. 


\section{Understanding the distributed practice effect and its relevance for the teaching and learning of L2 vocabulary}

Amanda Edmonds, Emilie Gerbier, Katerina Palasis and Shona Whyte

\section{Introduction}

1 Researchers working within the field of second language acquisition (SLA) draw on a wide body of work in order to understand the processes that underpin the learning of a new language. SLA research is thus informed by studies focused specifically on second language (L2) learning, but also by research from other fields that explore how learning occurs. Such fields include biology (see research on the critical period hypothesis, e.g., Hartshorne, Tenenbaum \& Pinker [2018]), sociology (i.e., research on L2 identity, e.g., Duff [2012]), and cognitive psychology. It is this final field that will be at the center of the present article. As noted by Lightbown [2008: 27],

[r]esearch in cognitive psychology is increasingly influential in second language acquisition (SLA) studies. It is one source of valuable guidelines for research in the classroom, helping us to shape the questions we ask about how language is learned, processed, remembered, used, and, in some cases, apparently forgotten. Psychological research on learning and retrieving what we have learned can provide insights into the processes underlying the learning that occurs in different types of second/foreign language instruction.

In this quote, Lightbown refers explicitly to instructed SLA, and references both language learning and language teaching. Although we agree that cognitive psychology research is now pervasive in much SLA research (see, for example, the explicit vs. implicit debate: Ellis [2002], or recent developments in usage-based approaches to language acquisition: Crossley, Kyle \& Salsbury [2016]), the influence of cognitive psychology is arguably less visible when it comes to informing teaching practice. Hilton 
[2019], for example, underscores the fact that communicative approaches to language teaching have developed independently of cognitive science research, and she argues forcefully that the field of language teaching research stands to gain from a greater openness towards and familiarity with cognitive science research. In the current article, we thus aim to provide an accessible synthesis of the cognitive science and SLA research that has addressed what Ellis [1995: 118] referred to as one of "the most robust phenomena in experimental psychology", namely the distributed practice effect. For this special issue on lexical learning and teaching, we focus on the specific question of how the distributed practice of learning episodes impacts the intentional learning of vocabulary in a L2. Our goal in so doing is to make the vast body of cognitive psychology research on this question available to interested teachers, teacher trainers and language learners.

3 This article is divided into four sections. In the first, we present and explain relevant terminology used in research on the distributed practice effect and on L2 vocabulary acquisition. In the second, we provide a short overview of research on the distributed practice effect with regards to learning in general. The third section presents research on the distributed practice effect with respect to L2 vocabulary learning in particular. Finally, the fourth section addresses explicitly how the findings with respect to the distribution of learning time can inform decisions with respect to language teaching and learning with regards to L2 vocabulary.

\section{Terminology}

\subsection{The distributed practice effect}

Over the past century, a large array of mostly laboratory-based studies has consistently shown differences in ultimate retention across individuals studying the same material for the same total amount of time and the same number of occurrences, depending on how study time is distributed (e.g., one 60-minute session vs. two 30-minute sessions over two days vs. two 30-minute sessions spread over one week). Overall, this research has demonstrated that more widely-spaced repeated learning episodes lead to better retention of intentionally learned material in the long term. This effect is referred to as the distributed practice effect. Unsurprisingly, the nature of the learning episode is also important, with researchers having compared review (where a participant is exposed to information to be learned) with retrieval practice (where the participant is required to recall the information in question). The following review will focus on the distributed practice effect and readers interested in review versus retrieval practice (i.e., the testing effect) may consult Rowland [2014].

5 Evidence for the distributed practice effect comes from studies that have compared the impact of different spacing (or distribution) intervals on ultimate learning. Most such research is based on a paired-associate paradigm, in which participants are asked to learn the association between two pieces of information (e.g., between a L2 word and a first language [L1] translation). These studies can be divided into those that have more specifically explored the spacing effect, and those that have focused on the lag effect. The spacing effect refers to the influence of learning episodes that are massed versus those that are spaced. Learning that takes place following a massed schedule involves two or more learning encounters of the same piece of information in a row, whereas a spaced 
schedule entails two or more learning encounters separated in time. To give an example, in the learning of L2 vocabulary, massed learning would involve studying the same L2-L1 word pair (e.g., pair A, B, or C) multiple times in succession (e.g., $A A A B B B C C C)$. In a spaced schedule, the learning episodes for the same word pair are separated in time, and this separation can take many forms. At the shortest end of the spectrum, one or more other pairs could intervene, creating space between the encounters with the first word pair, thus resulting in a spaced interval within a single learning session (e.g., $A B C B A C A B C$ ). Spaced intervals can also involve longer periods of time, with learning episodes separated by hours, days, weeks, months, and even years (e.g., $A B C$---- $A B C$--- $A B C$ ). Whether massed or spaced, the temporal interval between learning episodes is referred to as the inter-study (or inter-session) interval (ISI). For spaced intervals, the ISI can be organized according to two different broad types of schedules. More specifically, a learning schedule can have a uniform (equal/fixed) ISI, meaning that the same amount of time separates each learning interval (e.g., X-X-X) or an expanding ISI, whereby the spacing between learning episodes increases over time (e.g., X-X---X). ${ }^{1}$

6 Although the spacing effect focuses on the impact of massed versus spaced intervals on retention, in the real world, truly massed practice is rare (see Li \& DeKeyser [2019: 607]). In the learning of L2 vocabulary, it is indeed unusual to drill the same word multiple times in a row. What is arguably of greater relevance for (language) learning is what is known as the lag effect: the varying impact of differently spaced intervals to the exclusion of massed schedules. Research exploring the lag effect attempts to determine how study time may be temporally organized in order to optimize retention of newly learned material. The response to this question is not simple and, as we will see in section 2., depends crucially on both the ISI and what is called the retention interval (RI). The RI is the time that elapses between the final learning episode and the evaluation of the retention of learned material. Table 1 provides an overview of the different terms reviewed. ${ }^{2}$

Table 1. The distributed practice effect: Terminology and definitions

\begin{tabular}{|l|l|}
\hline Term & Definition \\
\hline Distributed practice effect & $\begin{array}{l}\text { the impact on subsequent retention of learned information of the } \\
\text { distribution of repeated learning episodes }\end{array}$ \\
\hline - spacing effect & $\begin{array}{l}\text { the impact of distributing repeated learning episodes according to } \\
\text { massed versus spaced intervals }\end{array}$ \\
\hline - lag effect & $\begin{array}{l}\text { the impact of distributing repeated learning episodes into spaced } \\
\text { intervals of different lengths }\end{array}$ \\
\hline $\begin{array}{l}\text { Spacing interval/Inter-study } \\
\text { interval (ISI) }\end{array}$ & $\begin{array}{l}\text { the amount of time that elapses between repeated learning episodes } \\
\text { for a single item }\end{array}$ \\
\hline - massed condition & $\begin{array}{l}\text { organization of repeated learning episodes that are consecutive (i.e., } \\
\text { the same item several times in a row) }\end{array}$ \\
\hline
\end{tabular}




\begin{tabular}{|l|l|}
\hline - spaced condition & $\begin{array}{l}\text { organization of repeated learning episodes that are separated in } \\
\text { time }\end{array}$ \\
\hline Spacing schedule & specific scheduling of successive ISIs \\
\hline - uniform/equal/fixed ISI & intervals of equal length separating learning episodes \\
\hline - expanding ISI & intervals of increasing length separating learning episodes \\
\hline Retention interval (RI) & $\begin{array}{l}\text { time separating the final learning episode and the testing of } \\
\text { retention }\end{array}$ \\
\hline
\end{tabular}

\subsection{Vocabulary acquisition}

Before discussing the distributed practice effect with respect to vocabulary acquisition, two pairs of terms from vocabulary acquisition research need to be clarified. The first pair - intentional versus incidental learning - concerns the focus of the learner's attention. In intentional vocabulary learning, the learner is told (or decides) to focus expressly on the learning of vocabulary. In language classrooms, this can take many forms, including form-focused tasks (e.g., matching, flashcards, crosswords, gapfill), but also more communicatively oriented activities before which the instructor may specifically ask learners to pay attention to certain words (perhaps even telling them that they will be tested on their knowledge later). In incidental learning, the learner's attention is directed toward another task - general text comprehension, participation in a dialogue task, etc. - instead of specific word learning. In experiments focused on incidental learning, participants are generally not informed of a subsequent vocabulary test. Much research has evaluated the effectiveness of intentional and incidental orientations on ultimate vocabulary learning outcomes, with most research demonstrating a stronger effect for intentional learning (see Uchihara, Webb \& Yanagisawa [2019]; Webb, Yanagisawa \& Uchihara [2020]). There is also a considerable body of research that has explored the distributed practice effect using L2 vocabulary as the learning target, the majority of which reports on intentional learning conditions. For these reasons, the present article focuses exclusively on distributed practice in intentional L2 vocabulary learning (see section 3.).

8 The second pair of terms refers to the aspects of vocabulary knowledge acquired by the learner. More specifically, a distinction is made between receptive and productive knowledge, with each covering a varied set of abilities. Nation [2001] provided an oftcited list of these abilities, which have been extensively used to design assessments of both types of knowledge. According to Nation, receptive vocabulary knowledge includes, for example, the ability to recognize a word's spoken form, to be able to give an appropriate definition for a word, and to choose an appropriate collocate from a set of possibilities. Productive vocabulary knowledge, on the other hand, involves the ability to produce a word's written form, to produce the word in question when the speaker desires to express the meaning to which it corresponds, and to produce idiomatic collocations in writing and speech. Research has consistently shown that receptive vocabulary knowledge precedes - and exceeds - productive knowledge of the same word forms (see González-Fernández \& Schmitt [2020]). This is an important 
point to keep in mind in interpreting the results from distributed practice with respect to L2 vocabulary learning, as some studies focus on one rather than the other type of knowledge in assessing learning.

\section{The impact of spacing on learning and subsequent memory}

The vast literature on the effect of distributed practice in human learning dates back to the first reports from experimental psychology (Ebbinghaus [1885]), and includes evidence from other disciplines, such as cognitive neuroscience, neurobiology, mathematic modeling, genetics, among others (for reviews, see Cepeda, Pashler, Vul, Wixted \& Rohrer [2006]; Toppino \& Gerbier [2014]). The distributed practice effect has been observed for children and adults using a range of materials (word pairs, images, motor skills, etc.). Moreover, similar effects have been observed in primitive species such as the sea slug or the fly, which suggest that it fulfills an essential adaptive function for memory. The focus here is not to review this literature (see Gerbier \& Toppino [2015]; Latimier, Peyre \& Ramus [2020]), but rather to provide a brief overview of what is known about the distributed practice effect. This overview will then serve as the backdrop against which we present research on how distributed practice may influence the intentional learning of L2 vocabulary (section 3.).

As stated in the previous section, the distributed practice effect refers to the fact that varying the temporal interval between repetitions (i.e., the ISI) for any given piece of information has an influence on how long it will be retained in memory. Thus, after encountering a new piece of information, there is an optimal moment at which to review it, with ISIs that are either too short or too long having been found to be suboptimal. Put simply, it has generally been found to be most effective to review information shortly before forgetting occurs. Why this may be the case has interested numerous researchers and resulted in several hypotheses. Three of these hypotheses have dominated the scholarly literature, and together help explain different components of the distributed practice effect (for more details, see Gerbier \& Toppino [2015]; Ullman \& Lovelett [2018]). The first - encoding variability - suggests that a piece of information is protected from forgetting when it has been "richly" encoded in memory. A piece of information is richly encoded when multiple and various cues allow an individual to subsequently access it. The encoding variability perspective suggests that longer ISIs lead to better memory outcomes precisely because widely-spaced learning intervals increase the probability that a given piece of information will be encountered in a wider variety of environments, thus enriching the memory trace associated with that piece of information. The second hypothesis is known as deficient processing. Central to this hypothesis is the idea that reviewing information too quickly after the first encounter (e.g., massed interval or narrowly-spaced intervals) is insufficiently demanding on the long-term memory system, presumably because the first activation is still present in short-term memory. As a result, less attention is allocated to attending to the new presentation, and the subsequent encoding of the information is weak. Thus, in the case of short ISIs, immediate retention tends to be very high (which may give the impression of successful learning), but retention levels quickly drop off later in time. In more widely-spaced ISIs, on the other hand, the information is no longer present in short-term memory at the second learning episode, 
necessitating deeper processing which, in turn, leads to greater long-term retention. The third hypothesis - study-phase retrieval - is based on the premise that subsequent learning episodes (i.e., repeated practice) can only improve memory if they succeed in reactivating the original memory trace. ${ }^{3} \mathrm{~A}$ repeated practice session that takes place too late - meaning that the original information has been forgotten - will not serve to reinforce previously learned material, but will rather result in a "starting over" of the learning process. However, if the repeated practice session is scheduled before forgetting, retrieval of the original memory trace is possible. Within this window of time, the study-phase retrieval hypothesis explains the difference between short and long ISIs in the following way: Retrieval practice that occurs shortly before forgetting will be more challenging, because of the weakening of the memory trace, and it is precisely this difficulty that leads to deeper processing and greater subsequent retention.

11 Both deficient processing and study-phase retrieval can be couched within a more general framework that helps explain distributed practice (and learning mechanisms, more generally), which is known as desirable difficulties (see Bjork \& Bjork [2011]). Desirable difficulties correspond to conditions that may create short-term challenges for learning but that ultimately optimize retention. Applied specifically to the language learning classroom, Bjork and Kroll [2015: 242] observed that:

conditions of instruction or practice that make performance improve rapidly often fail to support long-term retention and transfer, whereas conditions of instruction that appear to create difficulties for the learner, slowing the rate of apparent learning, often optimize long-term retention and transfer.

Contriving desirable difficulty can be a question of spacing (as discussed above) and/or type of task, where more demanding tasks (like those requiring retrieval from memory) are more effortful - and, thus, more beneficial to long-term memory - than simple exposure tasks (e.g., simply repeating or reviewing, see Latimier et al. [2020]).

So far, we have seen that in order to optimize learning, ISIs should be neither too short, nor too long. This overall general rule must, however, be nuanced by an interaction between ISI and the retention interval (RI). Put differently, there is no one single ISI that is most efficient across all timescales; instead, different RIs are associated with different optimal ISIs. In an oft-cited study, Cepeda, Vul, Rohrer, Wixted and Pashler [2008] asked participants to learn facts in two sessions that occurred according to various ISIs (ranging from 0 to 150 days). RI was also manipulated in this study, with participants either being tested on their retention of the facts 7 days, 35 days, 70 days, or 350 days (i.e., 6 months) after the second study episode. The authors demonstrated that the most effective ISI differed as a function of the RI: Best performance when testing occurred 7 days after the second learning episode was observed for the participants who had respected a 1-day ISI, whereas performance was best on the longest RI (6 months) among participants who had been assigned to the 21-day ISI. Thus, in general terms, the optimal ISI tends to be shorter when the RI is short, and longer when the RI is longer. Or, as seen from the perspective of forgetting, "when practice is spaced closely, it appears that forgetting occurs more quickly than when practice is spaced widely" (Pavlik \& Anderson [2005: 560]). On the basis of their results, Cepeda et al. [2006] suggested that optimal ISI may lie between $10 \%$ and $30 \%$ of the RI. Over the past decade, this proposed optimal ISI-RI ratio has inspired numerous studies, including several that have focused on L2 vocabulary learning. 


\section{The impact of spacing on language learning}

14 We turn now to the numerous studies that have specifically investigated how the spacing of learning episodes may influence retention of new L2 vocabulary words. As already specified, the present review is limited to distributed practice research involving intentional - as opposed to incidental - L2 vocabulary learning conditions. These studies differ in terms of the level of familiarity of learners with the foreign language in question. In one set of studies, the material to be learned includes words from a new language that the participants had never previously studied (and would perhaps never study again). The second group of studies explores the impact of the distributed practice effect among learners who are actually in the process of acquiring the L2 in question. Although the cognitive mechanisms underlying the learning of new words are presumably similar in the two cases, there are at least two crucial differences between these participant populations which may impact research findings.

15 First, participants who take part in an experiment for which they are asked to learn pairs of L1-L2 words involving an L2 of which they have no previous knowledge will presumably not be motivated to retain the new information beyond the duration of the experiment. In contrast, participants involved in a similar experiment involving a language they are currently learning may very well have the goal of retaining the new words in the long term, and this goal may influence learning outcomes. As noted by Küpper-Tetzel, Erdfelder and Dickhäuser [2014: 8], "it is not certain at all that the lag effect trends - as found in the laboratory - generalize to [...] authentic educational environments when material is learned that has immediate and future relevance for the population under investigation." Second, for participants discovering a previously unknown language through an experiment requiring them to learn L1-L2 word pairs, the only opportunity for learning is via the experimental presentation. This is in fact the reason why researchers have opted to use words from an unknown L2 in many distributed practice experiments: In asking participants to learn such words, researchers are able to ensure that participants have no previous knowledge of the words used in the study and no extra opportunities for learning between scheduled sessions. The situation is quite different for L2 learners, who already have a store of knowledge about the language they are learning, and who can - and presumably do mobilize that knowledge when encountering a new L2 lexical item. This already existing knowledge can aid in anchoring the new word. Given these differences, in what follows, we first offer a brief overview of studies having focused on L2 word learning involving a never-before-studied language (section 3.1.). We then dedicate more attention to the studies that are arguably of most interest to language teachers and learners, namely those that explore how the distributed practicing effect may influence intentional vocabulary learning when the new vocabulary words belong to a language that the learners are currently engaged in acquiring (section 3.2.).

\subsection{Learning words in an unknown language}

Research that has explored the distributed practice effect using L2 words from an unknown language paired with an L1 translation provides strong support for both the spacing effect and the lag effect (see Cepeda et al. [2006], and Toppino \& Gerbier [2014], for reviews). More specifically, learning is more effective when repeated learning 
episodes are spaced rather than massed, and research tends to show that wider ISIs lead to better memory retention. However, as already discussed, this finding is dependent on the RI. In addition to these robust effects, much recent research on distributed practice has explored the impact of schedule type on retention. More specifically, numerous authors have investigated how uniform versus expanding schedules influence ultimate retention. It has been hypothesized that expanding schedules may be beneficial to learning, insofar as they allow the learner to encounter a piece of information relatively quickly in the early stages of acquisition, making it more probable that the retrieval of that information will be accurate. This initial accurate retrieval is thought to then reinforce the memory trace, before subsequent practice is spaced more widely, which serves to facilitate long-term retention. Although studies on distributed practice using L1 verbal tasks (e.g., Maddox, Balota, Coane \& Duchek [2011]) or pseudo-word tasks (e.g., Toppino, Phelan \& Gerbier [2018]) have provided support for this hypothesis, ${ }^{4}$ the few studies that have explored the difference between expanding and uniform schedules with respect to the learning of novel words from an unknown L2 have reported no significant difference as a function of spacing schedule (Kang, Lindsey, Mozer \& Pashler [2014]; Karpicke \& Bauernschmidt [2011]; Pyc \& Rawson [2007]). As we will see in the following section, studies that have looked into the distributed practice effect using participants who are actual L2 learners (what we will refer to as the SLA research on distributed practice) have also addressed the spacing effect, the lag effect, and the impact of different spacing schedules. In addition, they have offered insight into several novel issues, which will be reviewed in section 3.2.4.

\subsection{Learning words in an $\mathrm{L} 2$}

\subsubsection{Methodological aspects}

17 In total, we have identified 20 studies that belong to SLA research on distributed practice with respect to intentional learning of L2 vocabulary. Although we have chosen to review these studies as a group, the reader should keep in mind that they show significant methodological variation, which may impact the consistency of findings. Differences with respect to four specific aspects seem to be particularly important. First, these 20 studies cover participants from a range of age groups, including adults (Bahrick, Bahrick, Bahrick \& Bahrick [1993]; Chukharev-Hudilainen \& Klepikova [2016]; Librenjak, Kocijan \& Janjić [2016]; Nakata [2015]; Nakata \& Suzuki [2019]; Nakata \& Webb [2016]; Schuetze [2015], [2017]; Schuetze \& Weimer-Stuckmann [2011]; Seibert Hanson \& Brown [2020]), but also students in elementary school (Lotfolahi \& Salehi [2016]; Rogers \& Cheung [2020], [in press]), middle school (KüpperTetzel et al. [2014]; Lindsey, Shroyer, Pashler \& Mozer [2014]; Moinzadeh, Talebinezhad \& Behazin [2008]), and high school (Bloom \& Shuell [1981]; Nakata [2008], [2017]; Serrano \& Huang [in press]). It is important to highlight this variety, because "the functionality of declarative and procedural ${ }^{5}$ memory seems to change over the course of childhood (and adulthood), [and thus] spacing and retrieval practice might be differentially effective for language learning at different ages" (Ullman \& Lovelett [2018: 57]). As such, certain results that appear inconsistent at first sight may in fact reflect age-related differences. 

widely. Whereas research using L2 words from unknown languages is dominated by cued-recall activities (where participants are shown an L1 word and required to provide the L2 translation), SLA research on distributed practice has capitalized on the fact that learners' previous knowledge of the L2 gives them the ability to engage in a wide range of (more or less contextualized) intentional vocabulary activities. Whereas some SLA researchers (in particular, Nakata) have opted to use the cued-recall activities typical of cognitive psychology research, authors such as Rogers and cheung [2020] have made a point of using ecologically-valid vocabulary activities that one might find in a typical L2 classroom. This difference is potentially important, as varying the learning activity can be expected to influence ultimate learning. Indeed, different activities will show different degrees of difficulty (i.e., the desirable difficulty framework mentioned earlier), a factor which may then interact with ultimate retention. studies. Most studies used cued recall, where the participants were given an L1 word and required to produce the L2 equivalent. This type of evaluation assesses one aspect of the participant's productive vocabulary knowledge. Other productive assessments used in these studies include gapfill tasks (Moinzadeh et al. [2008]) and crossword puzzles (Rogers \& Cheung [in press]). Some authors have preferred to assess receptive knowledge, using L2>L1 translation tasks (Bahrick et al. [1993]; Nakata \& Suzuki [2019]), multiple choice questions (Rogers \& Cheung [2020]), matching activities (Seibert Hanson \& Brown [2020]; Serrano \& Huang [in press]), and definition tasks (Lotfolahi \& Salehi [2016]). Finally, several studies have used both productive (L1>L2 translation) and receptive (L2>L1 translation) tasks to assess learning (Nakata [2015], [2017]; Nakata $\&$ Webb [2016]). Given that productive knowledge tends to develop after receptive knowledge, it seems reasonable to expect evidence of retention to be greater in those studies using receptive measures.

Finally, one-fourth of the reviewed studies examined ISIs that varied within a single session (Nakata [2008], [2015], [2017]; Nakata \& Suzuki [2019]; Nakata \& Webb [2016]). In other words, in these studies, the ISIs were very short, as they were defined in terms of intervening items. Nakata and Webb [2016], for example, compared retention results for participants who saw the same item separated by three intervening trials versus those who saw the same items separated by 19 intervening trials. This contrasts with all other studies, in which repeated encounters with a single word took place in distinct study sessions separated by at least 24 hours. Although both approaches constitute examples of distributed practice research, it remains unclear to what extent the same learning mechanisms underlie both.

21 In what follows, we offer a thematic review of what empirical research focusing on L2 learners reveals about the distributed practice of vocabulary. We begin by examining what these 20 studies can tell us about the two effects that are robustly supported by research using words from an unknown language, namely the spacing effect and the lag effect. We then turn to the contribution of this research to the debate on spacing schedules. To finish, we look at other questions that have been explored by one or a small number of studies and that may provide interesting insights into the distributed practice effect in SLA. 


\subsubsection{The spacing effect}

22 Five studies have included a massed learning condition compared to one or more spaced learning conditions (Bloom \& Shuell [1981]; Küpper-Tetzel et al. [2014]; Lotfolahi \& Salehi [2016]; Nakata [2015]; Nakata \& Suzuki [2019]). In both studies by Nakata, the spaced condition involved a narrow spacing interval, as trials with other items were used to space out encounters with a given word pair. For example, in Nakata [2015], three levels of spacing were compared to a massed condition. These three levels of spacing included short (where each encounter with a target item was separated by five intervening trials), medium (10 intervening trials) and long (30 intervening trials) intervals. The remaining studies compared a massed condition to more widely-spaced conditions: learning sessions were either separated by 24 hours (Bloom \& Shuell [1981]; Küpper-Tetzel et al. [2014]) or one week (Küpper-Tetzel et al. [2014]; Lotfolahi \& Salehi [2016]). Most of these studies included two RIs (both an immediate and a delayed posttest). Despite having defined the spaced condition in quite different ways, the results show a significant advantage of spacing over massed study in the data from all posttests. These findings are thus consistent with research that used L2 words from an unknown language as learning materials, and offer additional support for the spacing effect.

\subsubsection{The lag effect}

Much SLA research on distributed practice has been interested in determining how best to organize repeated learning sessions over time in order to facilitate retention. In other words, such studies focus on the lag effect. In a first set of studies, authors did not compare specific spacing intervals. Instead, Nakata [2008], Librenjak et al. [2016], Chukharev-Hudilainen and Klepikova [2016], and Seibert Hanson and Brown [2020] investigated vocabulary learning via online tutors that apply learning algorithms to space out vocabulary practice. Overall, the results suggest superior vocabulary retention with spaced learning (versus flashcards and list learning, see Nakata [2008]) and show that more time spent on spaced learning practice of L2 vocabulary leads to greater learning benefits (see, for example, Seibert Hanson \& Brown [2020]).

In a second set of studies, the lag effect was investigated by comparing retention across two or more spaced intervals. A total of nine studies with L2 learners have made such a comparison, and have explored a wide variety of ISIs and RIs (see Table 2). Six of these studies reported a significant impact of ISI, although the significant patterns show different tendencies. In studies using very different ISIs, Nakata and Webb [2016], Bahrick et al. [1993], and Lindsey et al. [2014] all showed that the more widely-spaced interval led to more effective retention. However, in two of the studies with younger learners - Rogers and Cheung [2020] and Serrano and Huang [in press] - the shorter (i.e., 1-day ISI) led to superior retention. Finally, the ISIs that were found to be most effective by Moinzadeh et al. [2008] were neither the shortest nor the longest. Their participants were tested at two RIs: the day after training finished and one month later. In the case of the first post-test, learning sessions distributed over six consecutive days were the most effective. For the delayed post-test, however, a more widely-spaced interval (i.e., every other day practice) led to best results.

For the remaining three studies, no significant difference was found among spaced conditions (Küpper-Tetzel et al. [2014]; Nakata [2015]; Rogers \& Cheung [in press]). 
Rogers \& Cheung offer several possible explanations for this finding. First, they evoke the possibility that "the benefits of distributed practice have been overstated in the literature and previous findings are not robust in the face of the increased variability present in authentic classroom environments" (Rogers \& Cheung [in press: 15]). This suggestion underscores the importance of ecological, classroom-based research because it can "broaden the evidence and validity of well-known memory effects for naturalistic learning environments." (Küpper-Tetzel et al. [2014: 24]). Second, Rogers \& Cheung offer some interesting thoughts on the interaction between ISI and RI. They highlight that many SLA researchers have relied on Cepeda et al.'s [2008] research to determine the most appropriate ratio between ISI and RI. As explained earlier, these authors suggested that best retention results may be obtained if the ISI is between $10 \%$ and $30 \%$ of the length of the RI. On the basis of their own results and those from previous studies, Rogers \& Cheung question whether this ratio is in fact applicable to authentic language learning contexts. Thus, whereas research using L2 learners provides support for the spacing effect (section 3.2.1.), SLA results are mixed with respect to the lag effect, and even point in the direction of findings that diverge from the broader set of cognitive psychology studies.

Table 2. The lag effect: Different ISIs and RIs

\begin{tabular}{|c|c|c|}
\hline Study & ISIs & RIs \\
\hline Nakata \& Webb [2016] & 3 trials vs. 19 trials & $\begin{array}{l}\text { immediate } \\
1 \text { week }\end{array}$ \\
\hline Nakata [2015] & 5 trials vs. 10 trials vs. 30 trials & $\begin{array}{l}\text { immediate } \\
1 \text { week }\end{array}$ \\
\hline Serrano \& Huang [in press] & 1 day vs. 7 days & $\begin{array}{l}4 \text { days (for 1-day ISI) } \\
28 \text { days (for 7-day ISI) }\end{array}$ \\
\hline $\begin{array}{l}\text { Rogers \& Cheung [2020, in } \\
\text { press] }\end{array}$ & 1 day vs. 8 days & 28 days \\
\hline Küpper-Tetzel et al. [2014] ${ }^{6}$ & 1 day vs. 10 days & $\begin{array}{l}7 \text { days (half of the } \\
\text { participants) } \\
35 \text { days (half of the } \\
\text { participants) }\end{array}$ \\
\hline Moinzadeh et al. [2008] & $\begin{array}{l}2 \text { sessions per day over } 3 \text { consecutive } \\
\text { days vs. } \\
1 \text { session per day over } 6 \text { consecutive } \\
\text { days vs. } \\
1 \text { session per day every other day vs. } \\
2 \text { sessions per week over } 3 \text { weeks vs. } \\
1 \text { session per week over } 6 \text { weeks }\end{array}$ & $\begin{array}{l}\text { next day } \\
1 \text { month }\end{array}$ \\
\hline Lindsey et al. [2014] & $\begin{array}{l}\text { within } 1 \text { week vs. } 1 \text { week vs. } \\
\text { personalized }^{7}\end{array}$ & $\begin{array}{l}\text { end of semester } \\
28 \text { days }\end{array}$ \\
\hline
\end{tabular}




\begin{tabular}{|l|l|l|}
\hline & & 1 year \\
Bahrick et al. [1993] & 2 years \\
3 years \\
5 years
\end{tabular}

\subsubsection{Uniform vs. expanding spacing schedules}

Most research on spacing schedules asks whether learning sessions are best organized in a uniform manner, or whether learners may benefit from more closely spaced learning episodes at the beginning of learning, with a gradually increasing spacing interval thereafter (i.e., an expanding schedule). The research focusing on this question with L2 learners presents a mixed set of results. Starting with the only SLA study to report evidence in favor of expanding schedules, Nakata [2015] implemented a single learning session based on cued-recall practice and then assessed retention using both receptive and productive translation tasks. The author reports that expanding schedules led to significantly better retention, but only as measured with a task assessing receptive knowledge (L2>L1 translation); performance on the productive task (L1>L2 translation) was not impacted by the spacing schedule. The remaining three SLA studies to have investigated expanding versus uniform spacing schedules focus on American university students of German (Schuetze [2015], [2017]; Schuetze \& WeimerStuckmann [2011]). These studies have either included learning sessions involving enhanced cued-recall practice (where L2 lexical items were prompted with "images, sound files, lexicogrammatical information, target language sample sentences, and intercultural information" (Schuetze \& Weimer-Stuckmann [2011:465])) or implemented review (as opposed to retrieval) practice, during which participants saw, heard, and had to copy down new L2 words (Schuetze [2015], [2017]). In addition, these three studies only assessed retention using a measure of productive knowledge. In Schuetze [2015], [2017], no significant retention difference was found as a function of expanding versus uniform schedule. In the largest scale (and longest) study, however, Schuetze and Weimer-Stuckmann [2011] report evidence in favor of a uniform schedule. In this study, learners used an online platform to regularly review vocabulary items over two semesters; retention was evaluated at the end of each semester, and a delayed post-test was administered the following year (approximately 9 months after the end of the first semester and 5 months after the end of the second semester). The authors report no difference for spacing schedule in the results obtained at the end of each semester. However, on the delayed post-test, learners assigned to the uniform spacing condition outperformed those in the expanding schedule condition.

In order to understand these apparently contradictory results, we suggest that it is important to focus on the methodological differences among these studies. In particular, they differ in terms of the type of learning activity used (cued-recall, enhanced cued-recall, review), the type of assessment measures implemented (receptive vs. productive), and the absolute durations of the ISIs. Keeping these differences in mind, it appears that reviewing new L2 words (as opposed to having to recall them) is not significantly impacted by spacing schedule, at least when retention is measured using productive tasks (which are generally more cognitively demanding than receptive ones, see Schuetze [2015], [2017]). Turning to the two studies that 
required participants to engage in recall tasks during learning (Nakata [2015]; Schuetze \& Weimer-Stuckmann [2011]), it appears that simple cued-recall may lead to better retention when practiced in an expanding schedule. However, it should be kept in mind that this difference was found to impact only receptive knowledge (L2>L1 translation) in a study involving very narrow ISIs. Enhanced recall, on the other hand, was found to be most effective when practiced in a uniform schedule spaced every other day, and this effectiveness was demonstrated using a productive assessment measure. This finding may suggest that enhanced cued-recall activities counterbalance the potential positive impact of expanding spacing. More specifically, expanding spacing is hypothesized to facilitate learning because it should help learners to correctly recall information during early encounters, allowing for the associated memory trace to be strengthened (i.e., successful study-phase retrieval). The results from this small body of research are compatible with the idea that the advantage of expanding spacing may lose potency with enhanced cued-recall, which by virtue of the variety of information presented, may already succeed in creating relatively richly detailed and perhaps more strongly anchored memories (i.e., encoding variability). It thus appears that L2 vocabulary recall practice may be influenced by spacing schedules, but that other factors (such as the richness of that recall) may modulate these effects.

\subsubsection{Other issues}

28 Each of the preceding points (the spacing effect, the lag effect, the role of spacing schedules) are issues that have received extensive attention in the larger cognitive psychology literature on the distributed practice effect. In this final section, we turn to three issues that have been addressed in one or in a small number of SLA studies and which may be of interest to teachers and learners alike. The first issue comes from Nakata \& Suzuki [2019]. These authors were interested in how the grouping of new vocabulary words into semantically-related (e.g., mammals: baboon, badger, otter, porcupine, raccoon, weasel) versus semantically-unrelated (e.g., alcove, pail, pigment, potassium, relic, toupee) lists may affect ultimate learning of these words. More specifically, they questioned whether massed versus spaced learning episodes would influence the learning of semantically-related and unrelated words differently. They hypothesized that semantic groupings would inhibit learning, because of the potential cross-associations between related words. With respect to spacing, they expected that the spaced condition would be superior to the massed condition for both semanticallyrelated and unrelated words, although they suggested that spacing may be more effective for semantically-related words, as it may help to counteract potential interference among words in the same list. The results from this study showed an overall superior effect for word learning in the spaced (versus the massed) condition. However, no difference was detected for semantically-related and unrelated word lists. The authors also found an interaction between semantic relatedness and spacing, but contrary to expectations, this interaction showed that unrelated words benefited most from spacing. To interpret these results, the authors called upon the desirable difficulties framework. In particular, they suggested that the use of semanticallyrelated word lists may indeed result in within-list interference, but that this interference is actually beneficial to the learning process, as it essentially makes the learner's task more difficult. And, in so doing, leads to more long-term learning. 

of Japanese high school students learned 16 new words in L2 English. Participants took part in a single learning session, during which they first saw a presentation of the new words before being required to engage in cued-recall practice (L1>L2 translation). Participants were divided into four groups, depending on how many times they cycled through the 16 words: once, three times, five times, or seven times. Although Nakata expected that repeated practice would lead to better retention on an immediate posttest as well as on a post-test administered one week after the learning session, he hypothesized that the benefit of repeated practice would have disappeared by the delayed post-test (4 weeks post treatment). This hypothesis was based on the distributed practice effect, as repeated practice with very short ISIs has been shown to benefit short-term (but not necessarily long-term) memory. Interestingly, Nakata found that participants who were in the 5 and 7 retrieval frequency groups outperformed those in the 1 and 3 frequency groups at each of the three post-tests. This finding highlights the importance of repetition (and, especially, repeated retrieval practice) in the intentional learning of L2 vocabulary, and suggests that it may lead to more durable learning than perhaps expected (see Nakata [2017: 672]). [2017]; Schuetze \& Weimer-Stuckmann [2011]). In addition to investigating the role of uniform versus expanded spacing schedules, the authors also focused on how the nature of the words to be learned may impact with the ultimate efficiency of learning as a function of type of spacing schedule. In particular, they included both content words (e.g., nouns: das Sonnenschutzmittel "the sunscreen", verbs: beabsichtigen "to intend", adjectives: notwendig "necessary") and function words (e.g., adverbs: vielleicht "perhaps", conjunctions: obwohl "although", prepositions: zwischen "between") in their study. These authors consistently find that retention is superior for content words, regardless of schedule type. To take Schuetze [2015, experiment 2] as an example, when learners were tested eight weeks after learning sessions had been completed, they were able to provide L1 $>\mathrm{L} 2$ translations for an average of approximately $75 \%$ of content words learned. For function words, averages were much lower, ranging between $19 \%$ and $30 \%$ of all words. Schuetze suggests that this difference may be due to the fact that "content words carry more information in terms of their lexemes and can therefore be discriminated using less [sic] repetitions than function words" [2015: 39]. The existence of potentially different learning trajectories associated with content and function words is clearly an important issue for both language teachers and language learners.

\section{Significance of distributed practice research for the teaching and learning of L2 vocabulary}

31 Vocabulary learning is essential to language learning, and given limited time, teachers and learners should be interested in how to optimize that learning. Distributed practice research can provide some guidance on this issue. In this section, we begin by identifying three specific points that are well-supported by research and showing how they can inform the teaching and learning of L2 vocabulary. We end by discussing two additional factors that future research may reveal to be important. 


\subsection{Repeated practice} practice. The research reviewed in the present article consistently drives home the point that repeated practice - and especially widely-spaced and more challenging practice, as we will see in the following sections - is essential to vocabulary learning. This observation may strike some readers as commonsensical: The more one practices, the better learning outcomes should be. However, the advent of communicative approaches to language teaching has led to decontextualized repetition and imitation falling out of style (see Hilton [2019: 36]). In addition, many teachers and learners may feel that dedicating classroom time to repetition is inefficient, and that their time may be better spent on new material. As a result, repeated practice is avoided in certain language classrooms, despite a growing body of research that highlights its merits (see Suzuki, Nakata \& DeKeyser [2019]). Interestingly, both distributed practice research and language teaching research have pled for repeated, gradually enhanced exposures to the same material. In distributed practice research, the encoding variability hypothesis suggests that repeated encounters with a new word enhance retention because they allow learners to enrich the memory trace associated with an L2 word. The enhanced memory trace is then less susceptible to forgetting. In language teaching research, Bruner [1960] and many others have argued for what is known as the spiral curriculum, a mainstay of constructivist educational practice that has been widely adopted in foreign language teaching (e.g., Carrell, Devine \& Eskey [1988]). Repeated exposure is central to the spiral curriculum, which holds that each encounter with an item (or concept, principle, etc.) should reinforce what is already known (i.e., repeated practice) while expanding or enriching the original knowledge base.

What might language teachers and learners take away from the idea that repeated practice is important? Very generally speaking, it is essential to recognize the important role of repetition in language learning (and, indeed, in most learning). Nevertheless, all repetition may not be equally effective. As we just saw, the encoding variability hypothesis and the spiral curriculum approach suggest that gradual elaboration with each encounter of a new lexical item may be particularly effective. In addition, teachers can reflect on how to use opportunities for repeated practice most effectively. For example, many language classes begin with a short review of material covered during the previous class. This is an excellent opportunity for repeated practice. One way to optimize this opportunity would be to not limit the review to only points discussed during the previous class time. Incorporating lexical items seen weeks and even months prior can enhance ultimate learning by introducing a more widelyspaced interval (see section 4.2.) which increases the difficulty of the retrieval practice (section 4.3.).

\subsection{Defining a retention interval and choosing an appropriate inter- study interval}

Bahrick et al. [1993: 320] observed that "[t]he life span of knowledge is an important, but neglected concern for educators and students." Within distributed practice research, the life span of knowledge refers, in effect, to the retention interval and, as we have seen, RI and ISI interact to yield optimal learning. In other words, it is essential 
that teachers and learners choose their desired RI (and associated ISI) with care. If the goal is simply to retain L2 vocabulary long enough to succeed on a test, then we know that shortly-spaced study episodes that immediately precede that test will be quite effective. However, we also know that such narrowly-distributed practice will result in relatively poor levels of long-term retention: Whereas shorter ISIs are most effective for shorter RIs, longer ISIs lead to better performance at longer RIs. This means that if the goal of teaching and studying a language is ultimately that learners gain a level of mastery in that language (as opposed to simply obtaining good grades), then both teachers and learners need to play the long game. For the teacher, distributed practice research suggests that teaching progressions should be designed at a much longer timescale than is normally the case. Instead of considering each teaching unit to be self-contained, it is essential to reflect on what learners should know at the end of the semester, the school year, or even at the end of several school years (e.g., at the end of middle school or high school). With respect to L2 vocabulary, this may involve identifying a list of essential lexical items that would need to be reactivated on a regular basis. The question then is how often words from this list would need to be reviewed (i.e., what ISI to apply). In research from Cepeda et al. [2008], it was found that best performance at the longest RI (which was 6 months post learning) occurred when 21 days separated two learning episodes. Although additional research is needed (particularly involving ecologically-valid learning conditions), this result provides some guidance, suggesting that reviewing at least some of the essential lexical items every three to four weeks may be an effective ISI for long-term retention. For learners, it is important to understand that long-term retention of vocabulary necessitates regular reactivation. Succeeding on an initial vocabulary quiz may give learners the impression of successful learning. However, without reactivation at relatively widelyspaced intervals, there is a real risk of forgetting. Reviewing past material is thus time well-spent. In addition, learners should be made aware of the fact that their performance will generally be lower on reactivation attempts than when tested shortly after initial learning, as this difference may cause frustration. Teachers can play a role here, namely by implementing regular vocabulary reactivation practice or quizzes for which credit is not based on accuracy, but rather on time spent or regularity of attempts made. In so doing, the teacher facilitates regular vocabulary retrieval, which will benefit long-term retention, even in cases where all retrieval attempts are not successful.

\subsection{Engineering desirable difficulties}

The general desirable difficulties framework can be applied not only to distributed practice effects, but also to other learning research. Put simply, the more difficulty involved in successfully retrieving a new piece of information, such as a new L2 word, the stronger the associated memory trace will be. Interestingly, this framework resonates with socioconstructivist perspectives on language learning, which hold that when a learner is faced with a difficulty, tailor-made, just-in-time assistance is most effective (e.g., Swain \& Lapkin [2013]). Although associated research findings are robust, both teachers and learners may avoid desirable difficulties. This is because both teachers and learners may associate successful and easy retrieval with successful learning. Indeed, distributed practice research on learners' perceptions has shown that they believe massed practice to be more efficient than spaced practice (see, for 
example, Kornell [2009]), presumably because massed (and narrowly-spaced) practice results in more successful learning in the short term. However, research shows us that successful and easy retrieval is often inefficient in the long term, presumably because it is not sufficiently challenging. This is precisely what is highlighted by the deficient processing model. Instead, effortful retrieval of the kind that is necessary after some time has passed between learning episodes is beneficial to learning (see the studyphase retrieval hypothesis). Both teachers and learners must be wary of practice that leads to high levels of success in the short term, and instead favor more difficult tasks that will, in the short term, appear to slow learning. It is precisely these more difficult tasks that are most beneficial for long-term learning. Given that this may be counterintuitive (not to mention frustrating) for students, we suggest that teachers explicitly explain the desirable difficulties framework to their students. This may serve both to change learners' expectations and habits, and also to reduce the possible stigma or frustration associated with (inevitable) forgetting.

\subsection{Future directions in distributed practice research}

36 In this final section, we briefly cover two factors that have received relatively little attention in distributed practice research, but which have the potential to strongly impact the influence of distributed practice in the learning of L2 vocabulary. First, although both the spacing and lag effect are robust, little research has focused on potential individual differences. And yet we know that individual differences - such as aptitude, motivation, learning strategies, working memory, etc. - play an essential role in guiding language acquisition (see the 2019 Language Learning supplement edited by Andringa \& DĄbrowska). Interest in individual differences is indirectly visible in distributed practice research in the form of adaptive algorithms used to space out practice as a function of an individual's previous responses (see Lindsey et al. [2014]). In addition, a recent study by Kasprowicz, Marsden \& Sephton [2019] on the distributed practice effect in the learning of French verbal morphology showed that one individual difference variable - language analytic ability - was significantly associated with posttest performance in their analysis. Despite growing interest, future distributed practice research on all aspects of L2 learning (e.g., vocabulary, morphology, etc.) will need to explore individual difference factors more fully.

Second, some of the SLA research on distributed practice has suggested that not all words may respond similarly to spacing effects. This was notably the case in Schuetze's research ([2015], [2017]; Schuetze \& Stuckmann-Weimer [2011]), in which retention of content words was superior to retention for function words. Although Schuetze does not find an interaction between word class and type of spacing schedule (uniform vs. expanding), no research addresses whether the spacing and lag effects show similar results for content and function words. Exploring this issue may contribute insights into the broader question of the connections between vocabulary and syntax in the cognitive architecture of language for L2 learners. In addition, the potential impact of other lexical characteristics (such as word length, part of speech, concept frequency, etc.) has received little attention. Exploring to what extent the characteristics of words may interact with the distributed practice effect has the potential to nuance what we already know about this phenomenon and to facilitate a more efficient transposition of research findings to the classroom. 


\section{Conclusion}

We hope to have shown that cognitive psychology research does indeed have much to offer to both language teachers and learners. In particular, we identify four take-away points from our review of distributed practice research as applied to the intentional learning of L2 vocabulary. First, this research suggests that language teachers and learners should create opportunities for repeated practice. Second, it is important to take a long view of learning, by identifying RIs that extend beyond a teaching unit (and any associated evaluations), in order to consider learning goals and outcomes over a longer timeframe. Third, teachers and learners need to be wary of learning activities that lead to quick success and, instead, search out activities that are desirably challenging. Finally, there is reason to believe that both differences at the level of the learner (aptitude, motivation, etc.) and at the level of the words being learned (length, imageability, etc.) may impact the distributed practice effect.

\section{BIBLIOGRAPHY}

ANDRINGA Sible \& DĄBROWSKA Ewa (Eds.), 2019, "Individual differences in first and second language ultimate attainment and their causes", Language Learning, 69(S1).

BAHRICK Harry P., BAHRICK Lorraine E., BAHRICK Audrey S. \& BAHRICK Phyllis E., 1993, "Maintenance of foreign language vocabulary and the spacing effect", Psychological Science, 4(5), 316-321.

BJORK E. L. \& BJORK Robert A., 2011, "Making things hard on yourself, but in a good way: Creating desirable difficulties to enhance learning”, in GERNSBACHER Morton A., PEW Richard W., HOUGH Leaetta M. \& POMERANTZ James R., Psychology and the real world: Essays illustrating fundamental contributions to society, New York: Worth Publishers, 56-64.

BJORK Robert A. \& KROLL Judith F., 2015, “Desirable difficulties in vocabulary learning”, The American Journal of Psychology, 128(2), 241-252.

BLOOM Kristine C. \& SHUELL Thomas J., 1981, "Effects of massed and distributed practice on the learning and retention of second-language vocabulary", Journal of Educational Research, 74(4), 245-248.

BRUNER Jerome, 1960, The process of education, Cambridge, MA: Harvard University Press.

CARRELL Patricia L., DEVINE Joanne \& ESKEY David E. (Eds.), 1988, Interactive approaches to second language reading, Cambridge: Cambridge University Press.

CEPEDA Nicholas J, vUl Edward, ROHRER Doug, WIXTED John T. \& PASHLER Harold, 2008, “Spacing effects in learning: A temporal ridgeline of optimal retention”, Psychological Science, 19, 1095-1102.

CEPEDA Nicholas J, PASHLER Harold, vUl Edward, WIXTED John T. \& ROHRER Doug, 2006, “Distributed practice in verbal recall tasks: A review and quantitative synthesis", Psychological Bulletin, 132, 354-380. 
CHUKHAREV-HUDILAINEN Evgeny \& KLEPIKOVA Tatiana A., 2016, "The effectiveness of computer-based spaced repetition in foreign language vocabulary instruction: A double-blind study", CALICO Journal, 33(3), 334-354.

CROSSLEY Scott, KYLE Kristopher \& SALSBURY Thomas, 2016, “A usage-based investigation of L2 lexical acquisition: The role of input and output", The Modern Language Journal, 100(3), 702-715. DUFF Patricia A., 2012, "Identity, agency, and second language acquisition", in GASS Susan M. \& MACKEY Alison (Eds.), The Routledge handbook of second language acquisition, New York: Routledge, 428-444.

EBBINGHAUS Hermann, 1885, Über das Gedächtnis: Untersuchungen zur experimentellen Psychologie, Leipzig: Duncker \& Humblot.

ELLIS Nick C., 1995, “The psychology of foreign language vocabulary acquisition: Implications for CALL", Computer Assisted Language Learning, 8, 103-128.

ELLIS Nick C., 2002, "Frequency effects in language processing: A review with implications for theories of implicit and explicit language acquisition", Studies in Second Language Acquisition, 24, 143-188.

GERBIER Emilie \& TOPPINO Thomas C., 2015, “The effect of distributed practice: Neuroscience, cognition, and education", Trends in Neuroscience and Education, 4, 49-59.

GONZÁLEZ-FERNÁNDEZ Beatriz \& SCHMITT Norbert, 2020, “Word knowledge: Exploring the relationships and order of acquisition of vocabulary knowledge components", Applied Linguistics, 41(1), 481-505.

HARTSHORNE Joshua K., TENENBAUM Joshua B. \& PINKER Steven, 2018, “A critical period for second language acquisition: Evidence from 2/3 million English speakers", Cognition, 177, 263-277. HILTON Heather H., 2019, Sciences cognitives et didactique des langues, Rapport d'expertise pour le Conseil national de l'évaluation du système scolaire, Conférence de consensus sur l'enseignement des langues vivantes, Paris : CNESCO ; also available at http://www.cnesco.fr/wp-content/ uploads/ 2019/04/190409_Hilton-1.pdf

KANG Sean H., LINDSEY Robert V., MOZER Michael C. \& PASHLER Harold, 2014, "Retrieval practice over the long term: Should spacing be expanding or equal-interval?", Psychonomic Bulletin \& Review, 21(6), 1544-1550.

KARPICKE Jeffrey D. \& BAUERNSCHMIDT Althea, 2011, "Spaced retrieval: Absolute spacing enhances learning regardless of relative spacing", Journal of Experimental Psychology: Learning, Memory, and Cognition, 37(5), 1250-1257.

KASPROWICZ Rowena E., MARSDEN Emma, \& SEPHTON Nick, 2019, “Investigating distribution of pratice effects for the learning of foreign language verb morphology in the young learner classroom", The Modern Language Journal, 103(3), 580-606.

KORNELL Nate, 2009, “Optimising learning using flashcards: Spacing is more effective than cramming”, Applied Cognitive Psychology, 23, 1297-1317.

KÜPPER-TETZEL Carolina E., ERDFELDER Edgar \& DICKHÄUSER Oliver, 2014, “The lag effect in secondary school classrooms: Enhancing students' memory for vocabulary", Instructional Science, 42(3), 373-388. 
LANDAUER T. K. \& BJORK R. A., 1978, “Optimum rehearsal patterns and name learning”, in GRUNEBERG M. M., MORRIS P. E., \& SYKES R. N., Practical aspects of memory, London: Academic Press, 625-632.

LATIMIER Alice, PEYRE Hugo \& RAMUS Franck, 2020, “A meta-analytic review of the benefit of spacing out retrieval practice episodes on retention", Educational Psychology Review, 1-29. doi:10.1007/ s10648-020-09572-8.

LI Man \& DEKEYSER Robert, 2019, "Distribution of practice effects in the acquisition and retention of L2 Mandarin tonal word production", The Modern Language Journal, 103(3), 607-628.

LIBRENJAK Sara, KOCIJAN Kristina \& JANJIĆ Marijana, 2016, “Improving students' language performance through consistent use of e-learning: An empirical study in Japanese, Korean, Hindi and Sanskrit", Acta Linguistica Asiatica, 6(2), 79-94.

LIGHTBOWN Patty, 2008, "Transfer appropriate processing as a model for classroom second language acquisition”, in HAN ZhaoHang (Ed.), Understanding second language process, Clevedon, UK: Multilingual Matters, 27-44.

LINDSEY Robert V., SHROYER Jeffery D., PASHLER Harold \& MOZER Michael C., 2014, “Improving students' long-term knowledge retention through personalized review”, Psychological Science, 25(3), 639-647.

LOTFOLAHI Amir R. \& SALEHI Hadi, 2016, “Learners' perceptions of the effectiveness of spaced learning schedule in L2 vocabulary learning", SAGE Open, 1-9.

MADDOX Geoffrey B., BALOTA David A., COANE Jennifer H. \& DUCHEK Janet M., 2011, “The role of forgetting rate in producing a benefit of expanded over equal spaced retrieval in young and older adults", Psychology and Aging, 26, 661-670.

MOINZADEH Ahmad R., TALEBINEZHAD Mohammad R. \& BEHAZIN Arash, 2008, "Exposure density in relation to learning and retention in EFL”, International Journal of Humanities, 15(2), 71-97.

NAKATA Tatsuya, 2008, "English vocabulary learning with word lists, word cards and computers: Implications from cognitive psychology research for optimal spaced learning", ReCALL, 20(1), 3-20.

NAKATA Tatsuya, 2015, "Effects of expanding and equal spacing on second language vocabulary learning", Studies in Second Language Acquisition, 37, 677-711.

NAKATA Tatsuya, 2017, "Does repeated practice make perfect? The effects of within-session repeated retrieval on second language vocabulary learning", Studies in Second Language Acquisition, 39, 653-679.

NAKATA Tatsuya \& SUZUKI Yuichi, 2019, "Effects of massing and spacing on the learning of semantically related and unrelated words", Studies in Second Language Acquisition, 41, 287-311.

NAKATA Tatsuya \& WEBB Stuart, 2016, “Does studying vocabulary in smaller sets increase learning? The effects of part and whole learning on second language vocabulary acquisition", Studies in Second Language Acquisition, 38, 532-552.

NATION Paul, 2001, Learning vocabulary in another language, Cambridge: Cambridge University Press. PAVLIK Jr. Philip I. \& ANDERSON John R., 2005, “Practice and forgetting effects on vocabulary memory: An activation-based model of the spacing effect", Cognitive Science, 29, 559-586.

PYC Mary A. \& RAWSON Katherine A., 2007, "Examining the efficiency of schedules of distributed retrieval practice”, Memory \& Cognition, 35(8), 1917-1927. 
ROGERS John \& CHEUNG Anisa, 2020, "Input spacing and the learning of L2 vocabulary in a classroom context", Language Teaching Research, 24(5), 616-641.

ROGERS John \& CHEUNG Anisa, in press, "Does it matter when you review? Input spacing, ecological validity, and the learning of L2 vocabulary", Studies in Second Language Acquisition.

ROWLAND Christopher A., 2014, “The effect of testing versus restudy on retention: A meta-analytic review of the testing effect", Psychological Bulletin, 140(6), 1432-1463.

SCHUETZE Ulf, 2015, "Spacing techniques in second language vocabulary acquisition: Short-term gains vs. long-term memory", Language Teaching Research, 19(1), 28-42.

SCHUETZE Ulf, 2017, "Efficiency in second language vocabulary learning", Die Unterrichtspraxis, $50(1), 22-31$.

SCHUETZE Ulf \& WEIMER-STUCKMANN Gerlinde, 2011, "Retention in SLA processing", CALICO Journal, $28,460-472$.

SEIBERT HANSON Aroline E. \& BROWN Christina M., 2020, "Enhancing L2 learning through a mobile assisted spaced-repetition tool: An effective but bitter pill?", Computer Assisted Language Learning, 33(1), 133-155.

SERRANO Raquel \& HUANG Hsiao-yun, in press, “Time distribution and intentional vocabulary learning through repeated reading: A partial replication and extension", Language Awareness, 1-19. doi: 10.1080/09658416.2021.1894162.

SUZUKI Yuichi, NAKATA Tatsuya \& DEKEYSER Robert, 2019, “Optimizing second language practice in the classroom: Perspectives from cognitive psychology", The Modern Language Journal, 103(3), 551-561.

SWAIN Merrill \& LAPKIN Sharon, 2013, “A Vygotskian sociocultural perspective on immersion education: The L1/L2 debate", Journal of immersion and content-based language education, 1(1), 101-129.

TOPPINO Thomas C. \& GERBIER Emilie, 2014, “About practice: Repetition, spacing, and abstraction”, in Ross B. H., The psychology of learning and motivation: Volume 60: The psychology of learning and motivation, Elsevier Academic Press, 113-189.

TOPPINO Thomas C., PHELAN Heather-Anne \& GERBIER Emilie, 2018, "Level of initial training moderates the effects of distributing practice over multiple days with expanding, contracting, and uniform schedules: Evidence for study-phase retrieval", Memory \& Cognition, 46, 969-978. UCHIHARA Takumi, wEBB Stuart \& YANAGISAWA Akifumi, 2019, “The effects of repetition on incidental vocabulary learning: A meta-analysis of correlational studies”, Language Learning, 69(3), 559-599.

ULLMAN Michael T. \& LOVELETT Jarrett T., 2018, "Implications of the declarative/procedural model for improving second language learning: The role of memory enhancement techniques", second Language Research, 34(1), 39-65.

WEBB Stuart, YANAGISAWA Akifumi \& UCHIHARA Takumi, 2020, "How effective are intentional vocabulary-learning activities? A meta-analysis”, The Modern Language Journal, 104(4), 715-738. 


\section{NOTES}

1. A third type of schedule, known as contracting, has been identified, but has received limited attention. For this reason, we will not include it in our discussion.

2. For clarity, our presentation of terminology is purposefully simplified. In particular, we have not acknowledged the sometimes inconsistent and ambiguous use of some of these terms. For example, spacing effect is often used as a synonym for the distributed practice effect. Moreover, the term massed is often employed to refer to narrowly-spaced intervals (especially within the same task or separated by a few hours).

3. The term "study-phase retrieval" must be understood here to refer to the cognitive mechanisms at stake during a study phase. When one encounters information, long-term memory automatically and involuntarily reactivates (i.e. retrieves) previous, related information. Importantly, this occurs during active testing but also during simple reviewing (although to different extents in both cases).

4. There also exists a small body of research on spacing schedules that uses other types of learning materials, such as face-name pairs (Landauer \& Bjork [1978, Experiment 2]).

5. Declarative memory has traditionally been considered to underlie explicit knowledge, whereas procedural memory underpins implicit knowledge. This distinction is actually more complex, and the interested reader might consult Ullman and Lovelett [2018: 40-43] for an overview.

6. As already mentioned, Nakata [2015] and Küpper-Tetzel et al. [2015] also included a massed condition (see section 3.2.1.).

7. This study included a spacing condition referred to as the personalized spaced scheduler, which relied on a Bayesian statistical model in order to program learning episodes. This resulted in different spacing schedules per participant per item. For our purposes, what is important is that the average spacing was largest for this condition (see p. 641).

\section{ABSTRACTS}

The distributed practice effect, which concerns the impact of the organization of learning time on the retention of repeated information learned, has inspired a large body of empirical research. Such research has generally shown, among other things, that longer temporal intervals between learning episodes (spaced learning) result in greater ultimate retention of new information, in comparison with both massed and more narrowly-spaced learning episodes. The distributed practice effect has been researched with respect to a wide variety of skills, including a rich body of research on how distributed practice may impact vocabulary learning in a second language (L2). In this article, we present the concepts and theories necessary to understand the distributed practice effect before offering an overview of studies that have focused on how L2 vocabulary learning may be influenced by distributed practice. Despite the large amount of sustained interest among researchers in this way of organizing learning, these robust findings are relatively unknown to language educators and language learners. Thus, after reviewing the relevant literature, we end by identifying how this research may fruitfully inform L2 vocabulary learning and teaching.

L'effet de pratique distribuée, qui réfère à l'impact de l'organisation de l'apprentissage sur la rétention d'une information répétée, a fait l'objet d'une vaste littérature empirique. Ces travaux 
ont montré, d'une façon générale, que de longs intervalles temporels entre les épisodes répétés d'apprentissage d'une nouvelle information (condition espacée) permettent une rétention en mémoire plus importante par rapport à des répétitions massées ou fortement rapprochées dans le temps. L'effet de pratique distribuée a été examiné pour une grande variété de types d'apprentissage, et on dispose en particulier d'une riche littérature sur cet effet pour l'apprentissage du vocabulaire d'une langue seconde (L2). Dans cet article, nous présentons les concepts et théories nécessaires pour comprendre l'effet de pratique distribuée avant de présenter une synthèse des études qui se sont focalisées sur l'apprentissage du vocabulaire L2. Malgré l'intérêt que les chercheurs ont porté à la façon d'organiser temporellement l'apprentissage, ces résultats robustes sont relativement méconnus des enseignants et des apprenants des langues. Ainsi, après avoir réalisé une revue de la littérature la plus pertinente, nous identifierons comment ces travaux peuvent contribuer à l'apprentissage et à l'enseignement du vocabulaire L2.

\section{INDEX}

Mots-clés: effet de pratique distribuée, effet d'espacement, langue seconde, vocabulaire

Keywords: distributed practice effect, spacing effect, second language, vocabulary, practice

\section{AUTHORS}

\section{AMANDA EDMONDS}

Université Côte d'Azur

amanda.edmonds@univ-cotedazur.fr

\section{EMILIE GERBIER}

Université Côte d'Azur

emilie.gerbier@univ-cotedazur.fr

\section{KATERINA PALASIS}

Université Côte d'Azur

katerina.palasis@univ-cotedazur.fr

\section{SHONA WHYTE}

Université Côte d'Azur

shona.whyte@univ-cotedazur.fr 